\title{
IMPROVEMENT OF AN AERIAL AND GROUND SPRAYING PERFORMANCE IN ORCHARD FIELDS
}

\author{
Samir. M. Youni*, Saad. F. Ahmed*, \\ and Fatma Farrag ${ }^{* *}$
}

ABSTRACT

Field tests were conducted in North Tahreer Company, the Spraying was done on Citrus trees. Two methods of spraying were used with both ground and aerial sprayers. For each method two tests were done with and without viscosity modifier. Samples were spread on the citrus trees to measure the droplet size, the spraying uniformity, the penetration inside the trees, and drift potential. Sensitive cards to the spray drops were used to collect the spray spectrum either on the top or bottom leaf surfaces. Better spraying performance with viscosity modifier was obtained by aerial application, method.

\section{INTRODUCTION}

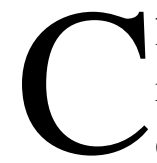

hemical pesticides have played and will continue to play a major role in the rapid advancement of agricultural production. Crop quality and yields have been improved and the use of chemical herbicides has greatly reduced labor requirements for weed control. But the widespread use of pesticides has resulted in some serious environmental and health problems. These problems are of direct concern to both the user and the equipment designer.

In recent years the aerial spraying of pesticides by aircrafts became one of the essential tools for pest control. In spite of presence of some limitation for using aircrafts such as certain weather conditions for application, drift problems, and some of obstacles such as trees and high building in addion to discollected large area, but the advantages of aerial application are the speed of application, elimination of out breaks, economics, and distribution of insecticide uniformity.

The obtained results of the first aerial spraying in A.R. of Egypt were encouraging, therefore the sprayed cotton area has been raised. Now in

\footnotetext{
* Professor of Ag. Eng., University of Alex.

** Ministry of Agriculture
} 
the large Agricultural Companies replace the ground spraying to aerial spraying in the large orchard fields. They decided to have this kind of change after they faced some problems such as non uniformity of spraying, low penetration, less coverage on the leaf surfaces, run off, labours shortage in the area, low field capacity and short seasons for spraying, machine problems, and high cost per feddan. Using aircraft spraying gives adequate (economic) control at a low cost per feddan compared with ground application.

The main objective of this research is to evaluate the ground and aerial spraying in the orchard fields, the viscosity modifier will be added in order to solve the drift problem.

\section{REVIEW OF LETERATURE}

Drift (aerial transport) from the treated area may result in poisonous or toxic chemicals being deposited on adjacent crops intended for either human or animal consumption. Some insecticide chemicals when eaten by dairy cows, tend to concentrate in the fats and milk, thereby creating a hazard in human consumption of these products, Yates, W. et al (1973). Drift of patent herbicides such as 2,4-D may cause injury to adjacent, susceptible crops. The drift problem is most acute for aircraft applications but is also evident when dusting or spraying with ground rigs.

Size is by far the most important particle property affecting the rate of fall and associated drift distances. Small particles settle more slowly than large particles because the aerodynamic drag forces are greater in relation to particle mass. For example, the theoretical distances that water droplets would be carried while falling $3 \mathrm{~m}$ in straight air flow having a uniform horizontal velocity of $4.8 \mathrm{~km} / \mathrm{h}$ would be only' $15 \mathrm{~m}$ for 100 microns droplets, but about $1.6 \mathrm{~km}$ for 10 micron droplets, El Nahas 1975. In actual practice, atmospheric turbulence would cause small particles, such as the 10 microns size, to be carried much farther than indicated by the theoretical, non turbulent.

Drift is minimized by employing atomizing devices that produce spray having large volume median diameters. For example, in aircraft tests, total drift deposits $305 \mathrm{~m}$ downwind were doubled when the VMD produced by the nozzles was decreased from 420 microns, to 290 microns Yates el al 1966. With the usual types of atomizing devices, increasing the VMB 
increases the size throughout the distribution spectrum, thus reducing the number of small droplets.

The first attempt of increasing viscosity was studied by Kaupke and Yates (1966) and Colthurst. (1966) They used an "inverted" or water-in-oil emulsion in order to increase the spray mixture viscosity. The inverts, however, had the disadvantages of being some what unstable, increasing photo toxicity and shifting rather than narrowing the droplet spectrum. Invert emulsions had been shown to reduce drift under many spraying conditions but was limited to use with phonexy acid-herbicides and certain insecticides where good coverage was not required. Cost-wise, they compared quite favorably with the newer thickeners on the market but presented more of logistics problem due to the large amount of oil needed.

Butler et al. (1969) used of spray adjuvants to reduce drift and they were comparing the 2-percent volume diameters for the different tests gives some indications of relative drift potential under of rank from smallest to largest 2-percent volume diameters were a)the un-,thickened spray, b) the Dacagin-modified spray. c) the vistik modified spray, and d) the Norbakmodified spray. It was interesting to note that the increases in volume mean diameter, in sauter diameter, in 2 percent volume diameter, and in volume median diameter were all in the same order as the apparent viscosities predicted for all four spray mixtures at the 10,000 - reciprocal seconds shear rate.

Later, Younis. (1973) studied the effect of subatmospheric air density on liquid disintegration with thickener material (Nalco-E 102). This material was named later by Nalco-Trol. The analysis showed a reduction in the fine drops and also a reduction in the evaporation rate even under high air velocity compared with water alone. In his study, the viscosity of the spraying liquid was measured at different shear rate and was found that the viscosity of the modifier fluid appeared to be approximately constant at high shear rates regardless of percentages of Nalco E 102. Therefore, it was recommended that the Nalco B-102 be used at about $0.1 \%$ concentration. At high shear rates present in the orifice of the pesticide nozzles, higher concentration would not increase liquid viscosity. Younis and El-Ashi (1978) studied the drift potential, and bioestimation 
test when a viscosity modifier was used. Very low percentages of NalcoTrol. ( 0.05 to $0.15 \%)$ were tested with two of nozzles: flat and swirl, and different size at low working pressures. Adding a very low percentage of Nalco- Trol to the spraying fluid reduced the driftable size- less than 200 microns. Nalco- troll and just the designed working pressure to give less percentage of the driftable size with high spraying performance. Higher percentage of Nalco-trol is added in windy days to reduce the evaporation from the droplets during their flights.

\section{MATERALS AND FIELD TESTS}

The main objective of this research is to compare the efficiency of ground and aerial spraying. The viscosity modifier added to the spraying solution may Improve the spraying process.

\section{The Ground Spraying}

The machine used in this test was a blower sprayer type, it was a mounted type driven by the PTO of the tractor. The sprayer tank capacity was 300 liters, the pump was reciprocating type with two cylinders, the nozz les were distributed on a circular pipe with a diameter of $75 \mathrm{~cm}$. The nozzles type was solid cone type. An axial fan with diameter of $50 \mathrm{~cm}$ was fixed in front of the -nozzles. The nozzles were oriented to direct the half of the spray pattern in the area of each side of the machine. A Massy Forgeson tractor $(44.7 \mathrm{kw})$ was used to mount the sprayer at a constant speed.

The solution used for this test consisted of water plus 2.5 liters of Dimethoate to give 300 liters of water per feddan. A viscosity modifier was added to the same solution to test the effect of spraying uniformity compared to the spraying solution without viscosity modifier. The material used as a viscosity modifier was Nalco-Trol imported from the U.S.A., specification of this material was reported in references Younis (1973). and Younis et al (1978). The specifications includes the viscosity, density and surface tension at different shearing rate, the recommended concentration is also included. It is recommended to use at the rate of $0.1 \%$

\section{The Aerial Spraying}

Aerial spraying was carried out with a Polish Helicopter model Mi-2. This 
type contains two rotors powered by two turbine engines. The tank capacity of the helicopter is 600 liters. The maximum of operating speed of the aeroplane was limited to $90 \mathrm{~km} / \mathrm{h}$. , the speed of flying, not during the spraying, reaches to $155 \mathrm{~km} / \mathrm{h}$ at flying height 50 meters above the ground. The helicopter contains a boom divided into three sections, one section is under the body and the other two sections are on the sides, The middle section contains 13 nozzles while the other sections contains 52 nozzles on each. The nozzles type is hollow cone type with 70 degrees spraying angle. The spacing between two adjacent nozzle is $12 \mathrm{~cm}$. the nozzle's tip diameter was 1.25 to $2.0 \mathrm{~mm}$.

During test, the recommended operating speed was $30 \mathrm{~km} / \mathrm{h}$ due to the height of wind breaks in the area. The application rate was 40 liters/feddan at $4 \mathrm{~kg} / \mathrm{cm} 2$ working pressure. The spraying width was $35 \mathrm{~m}$ for flying height 1-3 $\mathrm{m}$ above the trees surface.

Table (1) gives -the summary of spraying conditions during the test for both ground and aerial spraying.

Table ( 1) The Cumulative Percentage of the Droplet Size for Ground Spraying

\begin{tabular}{|c|c|c|c|c|}
\hline \multirow{3}{*}{ Classes in micron } & \multicolumn{2}{|c|}{ Without Nalco-trol } & \multicolumn{2}{|c|}{ With Nalco-trol } \\
\hline & \multicolumn{4}{|c|}{ Leaf Surface } \\
\hline & Upper & Lower & Upper & Lower \\
\hline $0-100$ & 0.3 & 0.8 & 0.2 & 0.6 \\
\hline $100-200$ & 10.0 & 17.0 & 7.0 & 13.0 \\
\hline $200-300$ & 27.0 & 42.0 & 19.0 & 35.0 \\
\hline $300-400$ & 36.0 & 59.0 & 31.0 & 55.0 \\
\hline $400-500$ & 53.0 & 75.0 & 43.0 & 68.0 \\
\hline $500-600$ & 71.0 & 100.0 & 56.0 & 91.0 \\
\hline $600-700$ & 80.0 & - & 73.0 & 100.0 \\
\hline $700-800$ & 100.0 & - & 83.0 & - \\
\hline $800-900$ & - & - & 100.0 & - \\
\hline
\end{tabular}

\section{Viscosity Modifier}

The thickner material which used as viscosity modifier was Nalco-Trol, It was supplied from Nalco-chemical. Company, Chicago, Illinois. This material is used in a liquid form and its viscosity was recorded in references number (8). However, the recorded viscosity was for Nalco E102 produced by the same company as Nalco-Trol which was indicated by the supplier.

\section{Measurements of Droplet Size}


The distribution of spray droplets and its size were measured by using a special cards. These cards were distributed on the trees at three different positions, the first at the top (A), the second one in the middle (B), and the third one at the bottom (C). Each position includes a sample for upper and lower leaf surface. The cards used to collect the spray droplets which are sensitive to the water, the spray droplet marked a spot without spreading on the cards. After collecting the cards, the droplet was measured by binocular eye piece divide into millimeters, the eye piece was calibriated before the measurements.

\section{The Field Test}

The field tests were conducted in north Tahrier company, El Nagah Farm. The farm was planted with citrus trees in row spacing 6 meters and the same distance between the trees within the row. Figure 1 shows the layout of the experiment for the ground spraying. The flow arrows show the travel direction of the sprayer. The dark and cross marks indicate the samples for the drift line on the trees and the ground respectively. Far ground spraying, two tests were conducted, one with the viscosity modifier and the second without the viscosity modifier. Each test was repeated three times. After the spraying process, the cards were collected and the droplets were measured with the eye piece. During the test, the following measurements were recorded such as wind speed, air direction, relative humidity and air temperature. The previous measuremented were obtained from the Meteorological physical Department of the North Tahrier Agricultural Company.

The layout for field tests with aerial spraying is shown in figure 2. The same experiments were done here as the ground spraying but tile flying height was introduced as a factor, they were 1,2 , and .3 meters above the trees.

To measure the penetration efficiency inside the trees, three samples were placed at three horizontal distances of the trees as it is shown in figure (3).

\section{RESULTS AND DISCUSSION}

The results obtained from the field tests are devided into the following section:
A. The Ground Spraying.
B. The Aerial Spraying. 


\section{Spraying Uniformity. \\ D. Drift.}

\section{A- The Ground Spraying}

Table (2) shows the cumulative percentage of the droplet size after they were classified into classes, the graphical presentation is shown in figures 4 and 5 for upper and lower leaf surfaces. It is clear that using the NalcoTrol (the viscosity modifier) with the spray solution increase the droplet diameter measured on both surfaces, this fact is due to high viscosity effect with the Nalco-Trol to produce larger drops and delaying into break-down near to the nozzles tip. The percentage increase was about $16 \%$ with the viscosity modifier for the upper surface, while this increase was about $10 \%$ for the lower surface. This reduction is due to the lower surface receives the smaller drops than the upper surface. At $50 \%$, the medium droplet diameters are 430 and 500 microns for upper surface without and with Nalco-Trol respectively, while these figures reach 300 and 330 microns for lower leaf surface with the same order. It is worth to note here, the average diameters are slightly higher under this spraying technique since the blower type sprayer was used in these tests which generate generally larger drops than other ground sprayers.

Figure (6) Shows the volume medium diameter at $50 \%$ for the three levels of the citrus trees, the three levels were at the top, medium and bottom of the tree. It is clear that the droplet diameter on the upper surface is higher than the lower surface, with Nalco-Trol is also higher than without. The effect of sample height is great on the upper surface than lower. For the lower surface the effect of the height level does not have effect on the spraying coverage, this is due to the lower surface receive drop size has the tendency to fly and rotate around the leaf and lay on the lower surface. For the upper surface, at 1.5 meters height, receives most the drops with any size because this height is the range of the spraying plast, while the one and three meters are not in the plast directly, so they receipe less medium diameter. It is clear that the average of this figure gives the same medium diameters which were obtained before that in figures 4 and 5 . To measure the penetration efficiency inside the trees, samples were distributed on the middle of the tree from outside to the tree center line, 


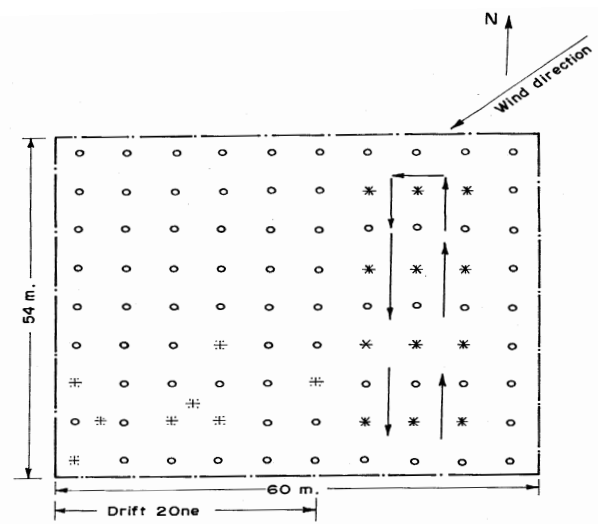

Fig 1: The Complete layout of the experiment for ground spraying o

Citrus trees * Sample on the tree $\quad \div \quad$ Drift sample

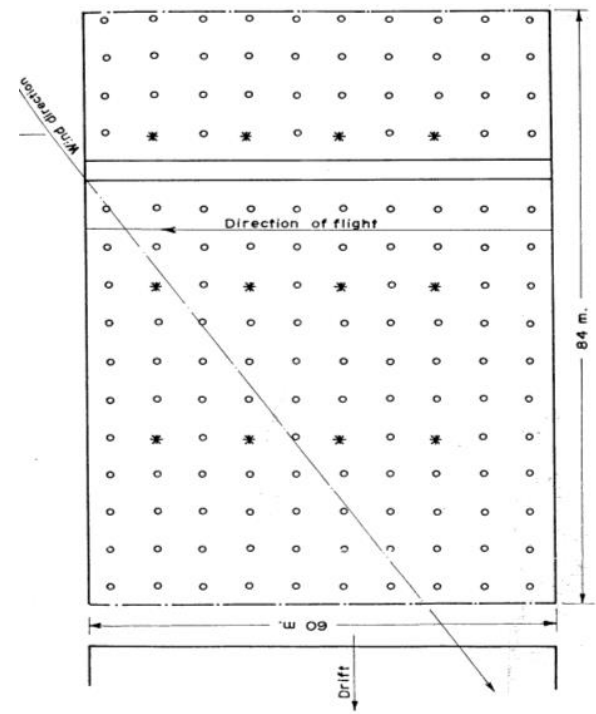

Fig 2: The complete layout of the expriment for aerial spraying

Citrus trees $*$ Sample on the tree

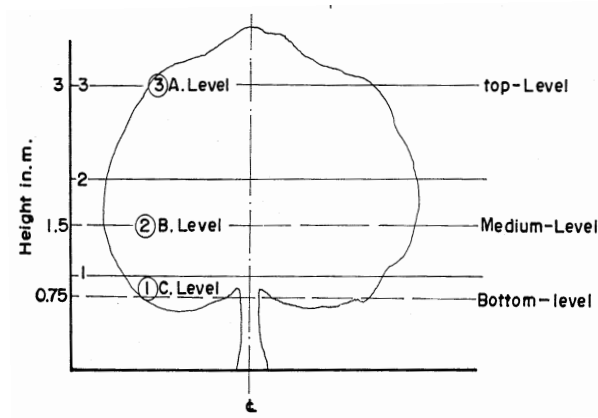

Fig 3: Samples for Penetration test 
Table (2): Droplet Size Data for Upper Leaf Surface of Helicopter-Spray

\begin{tabular}{|c|c|c|c|c|c|c|}
\hline \multirow{2}{*}{ Classes in micron } & \multicolumn{3}{|c|}{ Without Nalco-trol } & \multicolumn{3}{c|}{ With Nalco-trol } \\
\cline { 2 - 7 } & \multicolumn{4}{|c|}{ Helicopter heights, m } \\
\cline { 2 - 7 } & 0.2 & 0.5 & 0.5 & 0.2 & 0.43 & 0.3 \\
\hline $0-100$ & 4.0 & -6.6 & 8.3 & 2.3 & 4.20 & 6.2 \\
\hline $100-200$ & 14.0 & 23.5 & 27.0 & 7.4 & 13.30 & 19.7 \\
\hline $200-300$ & 26.0 & 36.1 & 38.6 & 16.1 & 23.60 & 34.0 \\
\hline $300-400$ & 42.0 & 54.1 & 56.5 & 28.0 & 40.40 & 51.0 \\
\hline $400-500$ & 67.0 & 87.0 & 89.2 & 44.4 & 60.50 & 72.5 \\
\hline $500-600$ & 89.0 & 100.0 & 100.0 & 62.2 & 83.00 & 91.5 \\
\hline $600-700$ & 100.0 & - & - & 83.0 & 100.0 & 100.0 \\
\hline $700-800$ & - & - & - & 100.0 & - & - \\
\hline $800-900$ & & &
\end{tabular}

Table (3): Droplet Size Data for Upper Leaf Surface of Helicopter-Spray

\begin{tabular}{|c|c|c|c|c|c|c|}
\hline \multirow{2}{*}{ Classes in micron } & \multicolumn{3}{|c|}{ Without Nalco-trol } & \multicolumn{3}{c|}{ With Nalco-trol } \\
\cline { 2 - 7 } & 1 & 2 & 3 & 1 & 2 & 3 \\
\hline $0-100$ & 0.29 & 1.0 & 1.6 & 0.24 & 0.6 & 0.4 \\
\hline $100-200$ & 8.20 & 11.8 & 17.3 & 4.20 & 6.8 & 10.0 \\
\hline $200-300$ & 25.30 & 32.9 & 40.0 & 18.50 & 22.4 & 30.8 \\
\hline $300-400$ & 42.00 & 57.0 & 65.1 & 26.00 & 38.7 & 55.8 \\
\hline $400-500$ & 70.00 & 83.6 & 100.0 & 45.00 & 65.4 & 80.0 \\
\hline $500-600$ & 100.00 & 100.0 & - & 65.00 & 90.0 & 100.0 \\
\hline $600-700$ & - & - & - & 100.00 & 100.00 & - \\
\hline $700-800$ & - & - & - & - & - & - \\
\hline $800-900$ & - & - & - & - & - & - \\
\hline
\end{tabular}

Table (4): Uniformity percentage for Ground Application

\begin{tabular}{|l|c|c|c|c|}
\hline \multirow{2}{*}{ Sample Levels } & \multicolumn{2}{|c|}{ Upper Surface } & \multicolumn{2}{c|}{ LowerSurface } \\
\cline { 2 - 5 } & Without & With & Without & With \\
\hline Top & 90.4 & 93.0 & 92.6 & 95.8 \\
\hline Medium & 95.5 & 97.0 & 92.0 & 92.0 \\
\hline Bottom & 94.4 & 95.5 & 90.0 & 92.7 \\
\hline
\end{tabular}

Table (5): Uniformity percentage for Aerial Application

\begin{tabular}{|l|c|c|c|c|c|}
\hline \multirow{2}{*}{ Sample Levels } & \multirow{2}{*}{$\begin{array}{c}\text { Helicopter heights, } \\
(\mathrm{m})\end{array}$} & \multicolumn{2}{|c|}{ Upper Surface } & \multicolumn{2}{c|}{ LowerSurface } \\
\cline { 3 - 6 } & & Without & With & Without & With \\
\hline \multirow{3}{*}{ Top } & 1 & 96.0 & 98.5 & 96.9 & 99.0 \\
\cline { 2 - 6 } & 2 & 96.2 & 96.0 & 98.5 & 98.0 \\
\cline { 2 - 6 } & 3 & 98.5 & 96.0 & 98.0 & 97.0 \\
\hline \multirow{3}{*}{ Medium } & 1 & 95.8 & 95.5 & 95.6 & 95.0 \\
\cline { 2 - 6 } & 2 & 96.6 & 95.8 & 95.4 & 96.5 \\
\cline { 2 - 6 } & 3 & 97.6 & 96.0 & 95.0 & 97.7 \\
\hline \multirow{3}{*}{ Bottom } & 1 & 96.4 & 97.4 & 97.5 & 96.0 \\
\cline { 2 - 6 } & 2 & 96.8 & 97.2 & 97.0 & 96.0 \\
\cline { 2 - 6 } & 3 & 98.5 & 96.0 & 95.4 & 98.0 \\
\hline
\end{tabular}


tree size was about 3 meters in diameter. Figure (7) shows the .coverage. percentage of the droplets using the spraying solution with and without Nalco-Trol, and the measuring included the upper and lower surfaces. It is clear that, the Nalco-Trol did not improve the penetration efficiency either on the upper nor the lower leaf surfaces. The penetration efficiency on the upper surface is better than the lower surface since the differences between the highest and lowest values for the upper surface are less than the lower surface. The penetration values are ranged between 24 to $7 \%$ for the upper surface, and 33 to $2 \%$ for the lower leaf surface, these figures are considered too high variation.

\section{B- The Aerial Spraying}

This experiment was similar to the ground spraying except the height is introduced as a factor here during the operation where, three heights were used 1,2, and 3 meters from the top of the trees to the spraying boom. Tables 2 and 3 show the cumulative percentage of the droplet size with and without Nalco-Trol with three different spraying heights, table 2 for upper leaf surface while table 3 for lower leaf surface. The graphical presentation is given in figures 8 and 9 for upper and lower leaf surfaces respectively. It is clear that the distribution of the droplets shifted uppward when Nalco-Trol viscosity

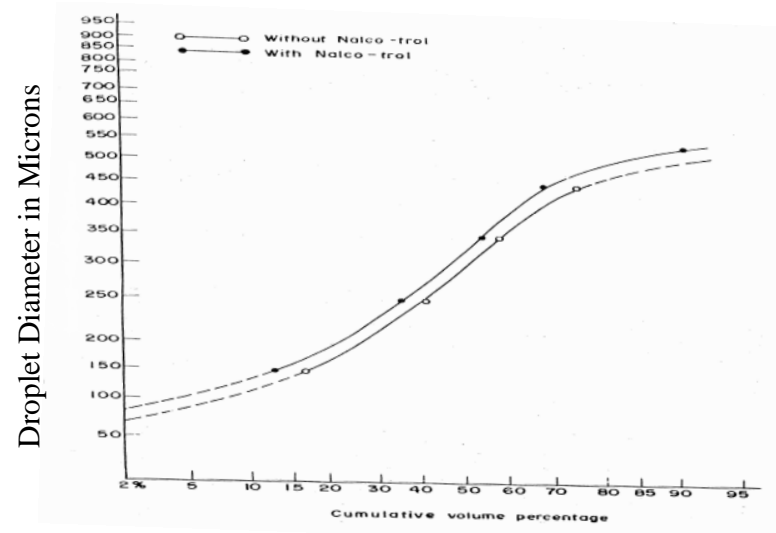

Fig 4: Droplet size distribution of upper leaf surface with ground spraying. 


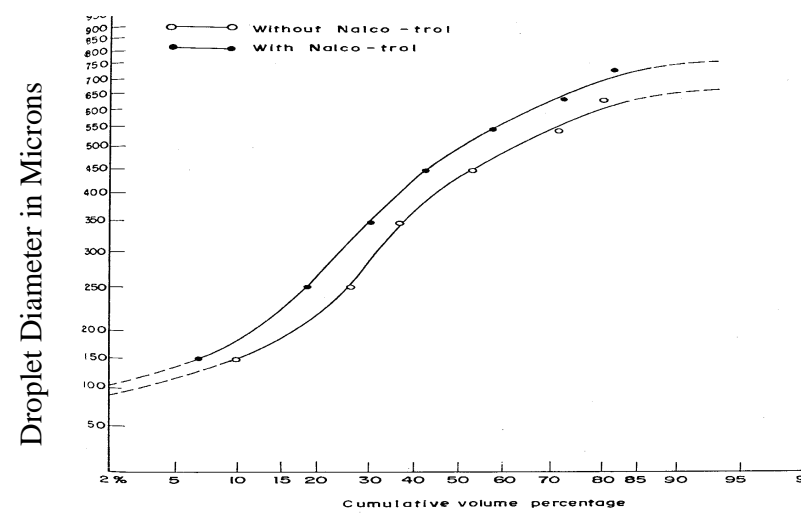

Fig 5: Droplet size distribution of Lower leaf surface with ground spraying

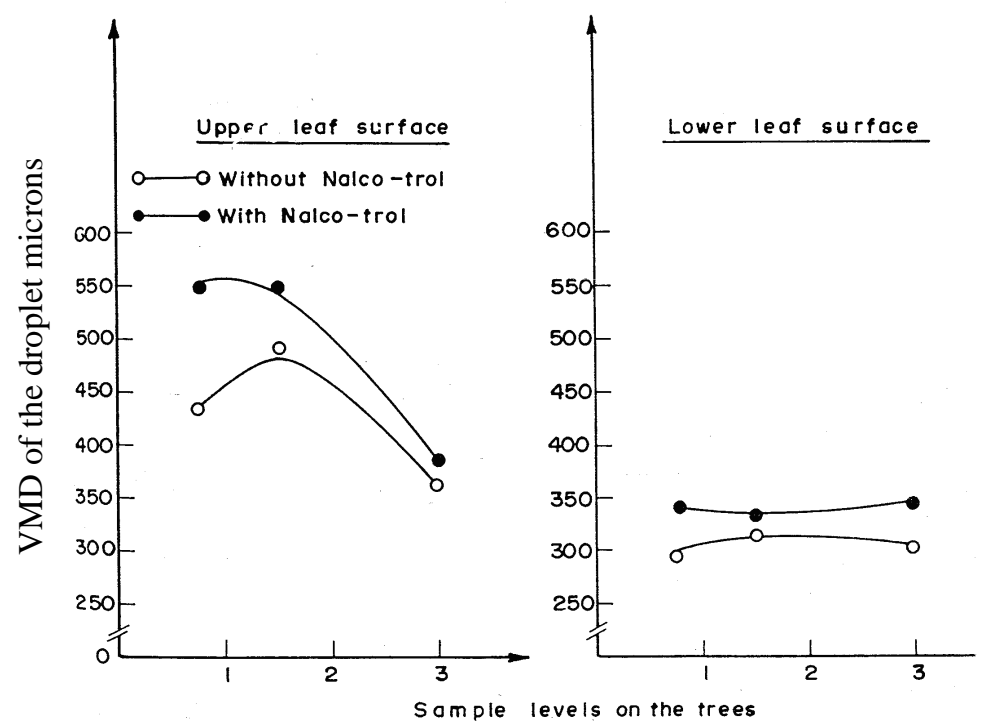

Fig (6): Droplet size diameter with different sample levels on the tree

\section{with ground spraying}

was added to the spraying solution, The effect of this material is extended to the three spraying heights either to the upper or lower leaf surfaces. The driftable size (at 200 microns) is reduced from $25 \%$ to $7 \%$ for upper surface and from 17 to $4 \%$ for lower surface when the Nalco-Trol was added. This reduction in the driftable size is due to higher viscosity presented in the solution gives higher droplet size.

The effect of the spraying height on the droplet size is very pronounced. The increase in the droplet size is about $8 \%$ when the spraying height decreases one meter level. So, it is recommended to spray on one meter height with using Nalco-Trol as the viscosity modifier. However, this 
height is a limited factor if the area of spraying is surrounded with wind breaks or electricity towers.

Figure (10) shows the value of volume medium diameter (at $50 \%$ ) for the three samples located at three levels of the tree (top, medium, and bottom).The spraying with Nalco-Trol VMD values are usually over that of spraying without, the difference is very small. The effect of the sample level has a smaller effect on the drop diameter where it is a little higher on the top sample than the bottom samples. The same trend is obtained with the upper and lower leaf surfaces.

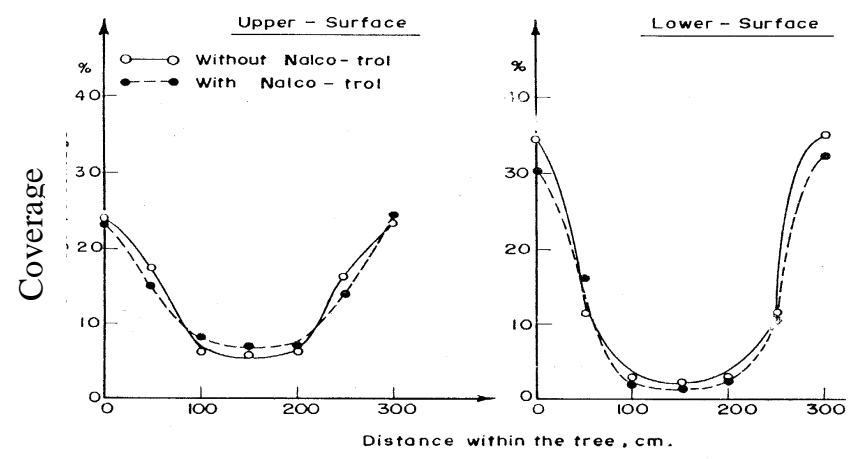

Fig (7): Droplet size Penetration on the tree with ground spraying

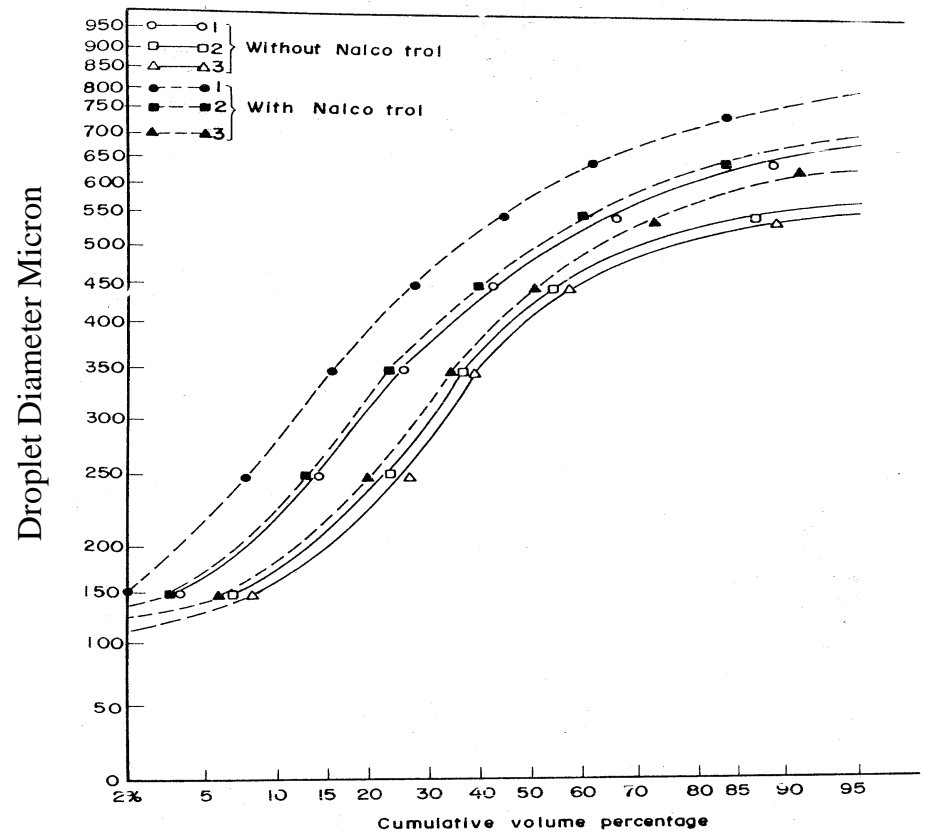

Fig (8): Droplet size distribution of upper leaf surface with aerial spray. 


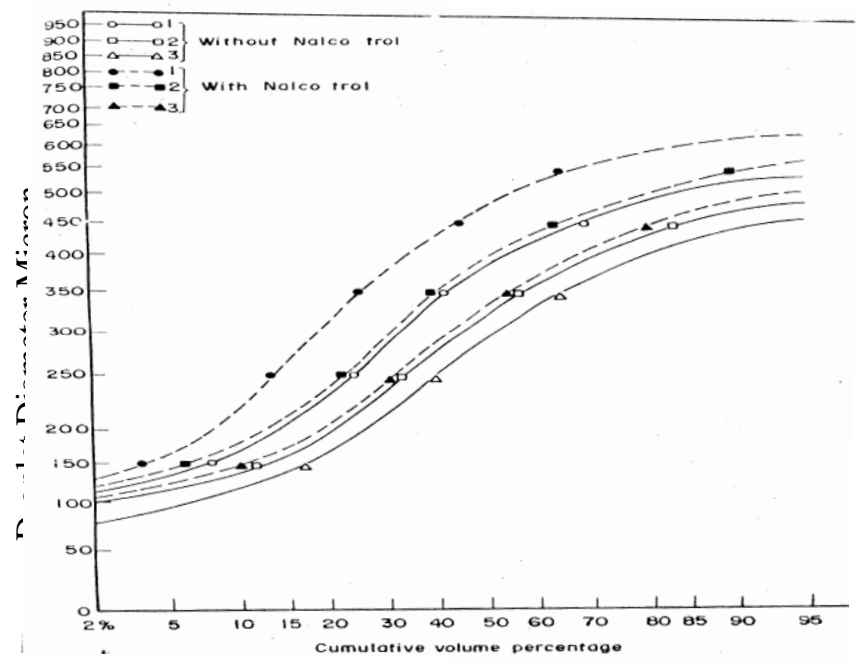

Fig (9): Droplet size distribution of Lower leaf surface with aerial spray.

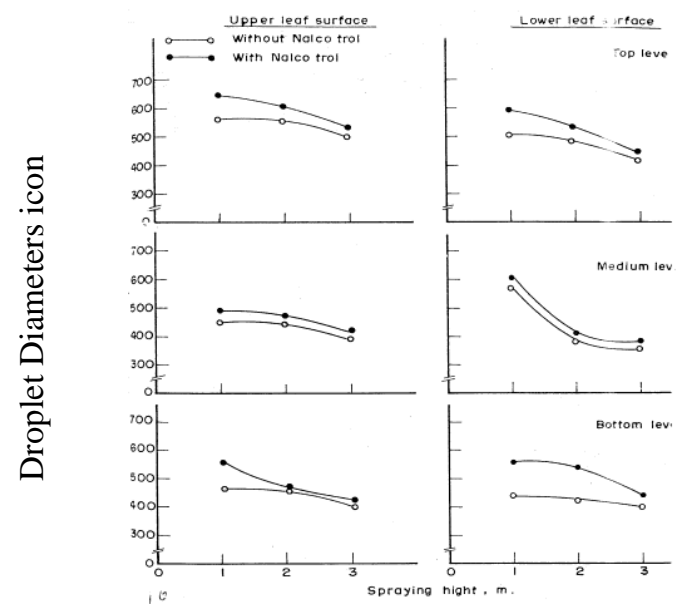

Fig (10):Droplet size diameter with different helicopter height with aerieal Spraying

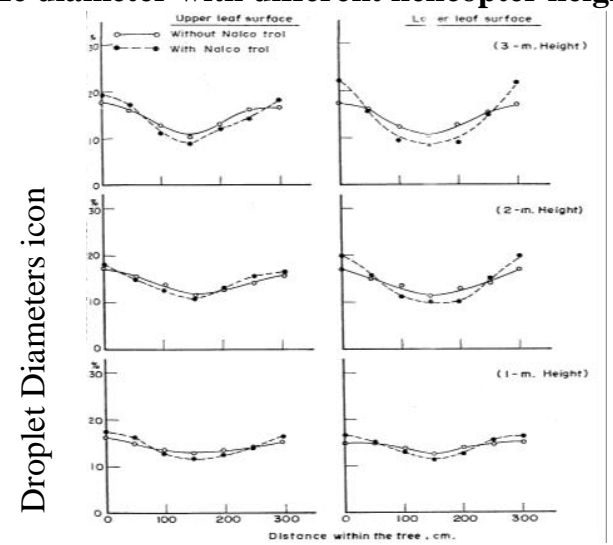

Fig (11): Droplet size Penetration on the tree with aerial spraying 


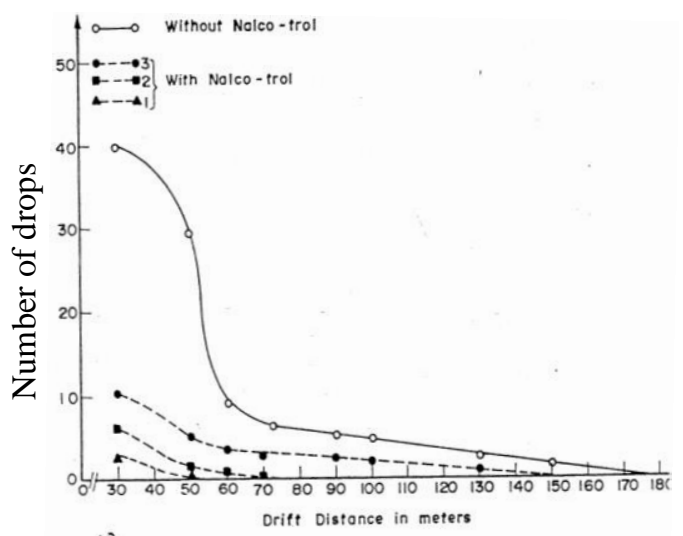

Fig (12): Drops number Vs Drift distance

Figure (11) shows the droplet penetration in the middle of the citrus tree at different spraying heights I, 2, 3 meter, respectively. The penetration is improved at lower spraying height. especially on the upper leaf surface. Adding the viscosity modifier to the solution reduces the penetration slightly. The effect of spraying height on lower leaf surface is very great than the upper leaf, at one meter height gives a better penetration even with Nalco-Trol that three meters height. The variation in the penteration is ranged between 12 to 16 at one meter height while it reached 9 to 19 at three meters height which is better than the figures obtailled previously with ground spraying. In respect with the droplet penetration, it is recommended to spray at height one meter, the viscosity modifier has less effect on the penetration.

\section{C- Spraying Uniformity}

The uniformity equation as written in references number (6) is:

$$
\mathrm{u}=\left[1-\left(\frac{\sum\left|\mathrm{x}_{1}-\overline{\mathrm{x}}\right|}{\mathrm{n} \overline{\mathrm{x}}}\right)\right] \times 100
$$

Where:

$$
\begin{aligned}
\mathrm{U}\left|\mathrm{x}_{\mathrm{i}}-\overline{\mathrm{x}}\right|= & \begin{array}{l}
\text { Uniformity Percentage } \\
\text { the Sum of the absolute deviaton of individual observations }\left(\mathrm{x}_{\mathrm{i}}\right) \text { from }
\end{array} \\
\mathrm{n} & =\begin{array}{l}
\text { The number of observation. }
\end{array}
\end{aligned}
$$

Tables 4, 5 show the uniformity percentage for ground and aerial application respectively. In general the uniformity percentage for the ground application is less than the aerial application. The uniformity is ranged between 90.4 to $97.0 \%$ for the ground application, while this range 
is reached to 95.0 to 99.3 for aerial application. The uniformity is Improved by aerial application due to the spraying turbalance in the area of spraying was generated by aeroplane.

\section{D- Drift}

It was planned to measure the drift for the ground and aerial and aerial spraying, but during the spraying tests with the ground sprayer the drops aid not spread far enough on the driftable line, the droplets reached about 6 meter from the spraying center line. So the measurements were done only for aerial application where the drift hazard is the main problem by this procedure.

Figure (12) shows the number of drops fall in the sample area at different distances from the spraying line, tests were conducted with and without Nalco- Trol for aerial spraying at different spraying heights. It Is clear that the effect of Nalco- Trol on the drift is very height since it reduced the number of drops to about $75 \%, 87 \%, 92 \%$, at 3, 2 and 1 meters heights respectively, This reduction was done with respect to the line of drift without Nalco- Trol at 3 meters height. These reductions were due to larger droplets introduced with the thickner material which was added to the spraying solution,.

\section{CONCLUSION}

The Conclusion drawn out of this research is better to use aerial spraying than the ground equipment. Better spraying uniformity, better penetration and drift with the viscosity modifier will be archived. The aerial spraying is recommended to use for pest control especially in orchard fields.

\section{REFERANCES}

Brooks, F. A. 1947. The drifting of poisonous dusts applied by airplanes and land rigs. Agr. Eng., 28 : 233 - 239, 244.

Butler, B. J., N. B. Akesson, and W. E. Yates. 1969. Use of spray adjuvaants to reduce drift. Trans of ASAE. Vol. 12 (2) (182-186).

Colthurst, J. P. 1966. Water- In- Oil emulsions and the control of spray drift. SCI. Monograph. No. 21.

Farag, F.(1986). Important of aerial and ground Spraying Performance in orchard. M. S., Ale aria uncrate.

Yates, W. E., and N. B. Akesson. 1973. Reducing pesticide chemical drift 
pesticide formulations. Physical Chemical Principles, Chap. 8. W. Van Valkeburg, Editor. Macel Dekker, New Yourk.

Yates, W. E., N. B. Akesson, and H. H. Coutts. 1966. Evaluation of drift residues from aerial application. Trans. Of ASAE, 9 (3): (389 - 393), 397.

Younis, S. M. 1973. Effect of Thickener and lowered air density on spray drop formation and evaporation rate. Unpublished $\mathrm{Ph}$. D. Thesis, Univ of Illinois Library.

Younis, S. M., and M. E. El - Ashi 1978. Reducing drift hazards during the spraying process. Alex J. Agric Res 26 (1) 1 - 20.

مصطفى محمد النحاس (9v0 ( ) "الطير ان الزر اعى فيى مصر ". المركز الدولى للتعليم الوظيفى للكبار فى العالم العربى - سرس اللبان - المنوفية ـ مصر - الطبعة الثانية.

الملخص العربيى

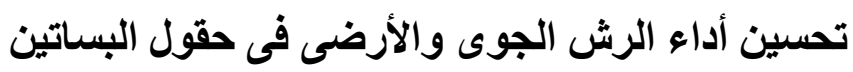

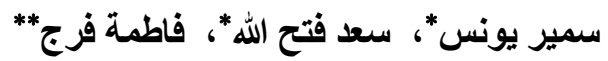

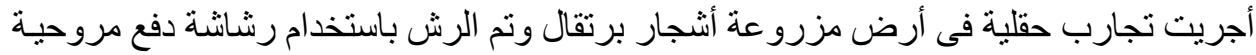

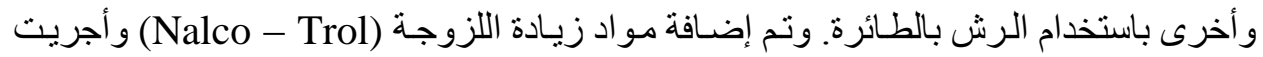

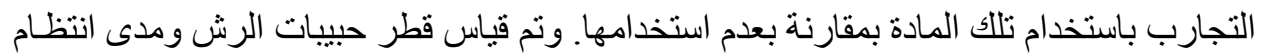

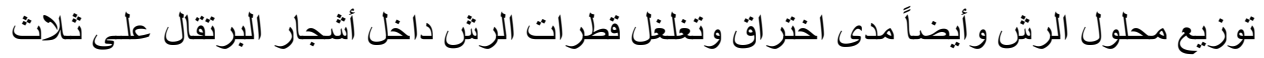

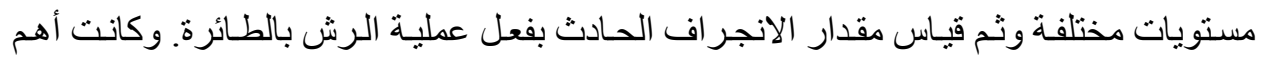

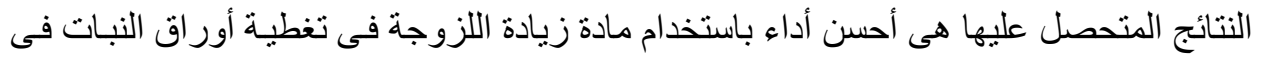

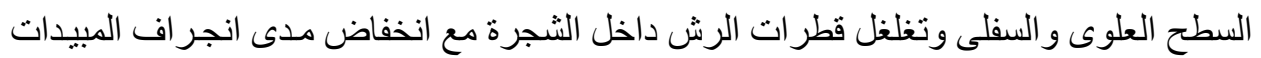
باستخدام الرش بالطائرة.

* أستاذ بقسم الهندسة الزر اعية - جامعة الإسكندرية. (مهندس زر اعى بوزارة الزراعة ـ الإسكندرية 